\section{Sustentabilidade financeira e econômica do gasto público em saúde no nível municipal: reflexões a partir de dados de municípios mato-grossenses}

\author{
Financial and economic sustainability of public \\ spending on health care by local governments: \\ an analysis of data from municipalities \\ in Mato Grosso State, Brazil
}

\author{
${ }^{1}$ Instituto de Saúde Coletiva, \\ Universidade Federal de \\ Mato Grosso, Cuiabá, Brasil. \\ 2 Faculdade de Medicina, \\ Universidade de São Paulo, \\ São Paulo, Brasil. \\ ${ }^{3}$ Faculdade de Saúde \\ Pública, Universidade de São \\ Paulo, São Paulo, Brasil. \\ Correspondência \\ I. H. G. Scatena \\ Instituto de Saúde Coletiva, \\ Universidade Federal de \\ Mato Grosso. \\ Av. Haiti 193, apto. 1604, \\ Cuiabá, $M T$ \\ 78060-618, Brasil. \\ jscatena@ufmt.br
}

\section{Abstract}

Brazil's Unified National Health System is financed according to a model known as fiscal federalism, the fund-sharing rules of the Social Security Budget, Ministry of Health norms, and Constitutional Amendment 29 (EC-29), which links Federal, State, and municipal resources to health. This article discusses the sustainability of public spending on health at the municipal level. Twenty-one municipalities were studied, using municipal budget data. From 1996 to 2006, total current per capita revenues increased by $280 \%$ above the accumulated inflation and Gross Domestic Product, varying by size of municipality, which also defined the composition of the municipal budgets. Meanwhile, the budget comprising the basis for EC-29 increased less (178\%), thus placing limits on the municipal share of health spending. The results observed in these municipalities are believed to reflect the reality in thousands of other Brazilian municipalities, thus jeopardizing the capacity for municipal investment in health, especially beginning in 2008. The situation may become even worse, considering the repeal of the so-called Bank Transaction Tax (CPMF), Bills of Law 306/08 and 233/08 (currently under review in the National Congress), and the world recession stemming from the U.S. financial crisis.

Single Health System; Health Financing; Health Expenditures; Decentralization
João Henrique Gurtler Scatena ${ }^{1}$

Ana Luiza d'Ávila Viana 2

Oswaldo Yoshimi Tanaka 3

\section{Introdução}

Embora os municípios façam parte da organização político-administrativa do Brasil desde a sua primeira Constituição (1824), do período imperial, eles somente aparecem explicitamente referidos como entes federados na Constituição Federal de 1988 1,2. Essa Constituição, ao definir as competências de cada um dos entes federados, caracteriza-as como exclusivas, privativas, comuns, concorrentes e suplementares.

Entre as competências comuns da União, dos estados, do Distrito Federal e dos municípios, sobressai-se "cuidar da saúde e assistência pública, da proteção e garantia das pessoas portadoras de deficiência" (Constituição Federal de 1988; Art. 23, II). Especificamente aos municípios, compete "prestar, com a cooperação técnica e financeira da União e do Estado, serviços de atendimento à saúde da população" (Constituição Federal de 1988; Art. 30, VII). É, no entanto, em seção específica dessa Constituição (Art. 196 a 200) que a concepção de saúde é ampliada, o Sistema Único de Saúde (SUS) é instituído e os princípios de seu financiamento são estabelecidos.

Ao abordar o tema do financiamento da saúde, há que se ressaltar, inicialmente, que em inúmeros países do mundo, parcela significativa das despesas com saúde não recai sobre o setor público. Dados estimados para 2003, selecionados pelo Conselho Nacional de Secretários de Saúde (CONASS) 3, do World Health Report 2006, 
informam que a participação do setor público nas despesas com saúde era inferior à do setor privado em 7 dos 9 países com população maior que 100 milhões de habitantes, o Brasil entre eles, com somente $45,3 \%$ das despesas sob responsabilidade do setor público. Isso também se deu em 6 dos 7 países membros ou associados do MERCOSUL. Já quando o Brasil é comparado a outros cinco países com sistema de saúde de acesso universal, aquele percentual se destaca, negativamente, dado que o gasto público representa percentuais entre 68\%, na Austrália e 95\%, na Suécia.

A estimativa informada pela Organização Mundial da Saúde (OMS) aproxima-se daquela encontrada por Ugá \& Santos 4, que, com base em dados da Pesquisa de Orçamentos Familiares (POF), do Sistema de Informação sobre Orçamentos Públicos em Saúde (SIOPS) e da Agência Nacional de Saúde (ANS), observaram que, em 2002, 44\% das despesas com saúde ficaram sob responsabilidade do setor público, enquanto o restante foi despendido pelas próprias pessoas: $34 \%$ com gastos diretos e $22 \%$ com planos ou seguros de saúde. A fração do gasto público provavelmente aumenta se são consideradas também as isenções e as renúncias fiscais embutidas naqueles gastos privados. Dados de 2005, do Sistema de Contas Nacionais informam que, em termos de consumo final, $61 \%$ dos bens e serviços produzidos pelo setor saúde são pagos pelas famílias, enquanto que apenas $39 \%$ o são pela administração pública 5 .

A relação de gastos públicos e privados provavelmente varia muito em distintos pontos do Brasil, dada a heterogeneidade demográfica, social e econômica entre regiões, estados e municípios brasileiros, estimando-se percentuais de gastos públicos tanto maiores quanto piores os indicadores sócio-econômicos destas unidades. Mediante tal cenário, admite-se a limitação de um recorte voltado apenas para o financiamento público da saúde, mas salienta-se tratar-se do financiamento do SUS, sistema nacional de acesso universal, e principal - quando não exclusiva forma de acesso aos serviços de saúde para mais de $70 \%$ da população brasileira. Soma-se a isso o fato de que as informações sobre receitas e despesas públicas são as únicas rotineiramente disponíveis e de acesso universal, o que foi possível com a criação do SIOPS, em 1999 6, e que naquele ano já havia captado dados de mais de $60 \%$ dos municípios brasileiros, relativos a 1998.

No Brasil, o financiamento público da saúde, enquanto tema de discussão acadêmica da área de Saúde Coletiva, tem destaque em artigo do número inaugural da Revista de Saúde Pública, reimpresso em 2006 7 . Ainda que restrito ao que o autor chamava de "serviços sanitários, ou seja, das atividades estatais de saúde pública” 7 (p. 560), tal financiamento apresentava importante relação com a forma, a distribuição e a magnitude da arrecadação pelos entes que compunham, à época, o pacto federativo brasileiro. No que tange à arrecadação de receitas, no período analisado por aquele autor (1930 a 1962), observava-se o nível federal concentrando entre $59 \%$ e $51 \%$ da arrecadação, o nível estadual entre $30 \%$ e $42 \%$ e o nível local entre $12 \%$ e $5 \%$. Por volta de meio século depois (2005), em termos de arrecadação, a União concentrava $67,8 \%$ das receitas, os estados $26,7 \%$ e os municípios $5,5 \%$, percentuais que, após a redistribuição prevista na Constituição, redundam em $56,7 \%$ para a União, $25,2 \%$ para os estados e $17,2 \%$ para os municípios ${ }^{8}$. Ressalta-se que, entre esses dois recortes temporais, cinco Constituições (1934, 1937, 1946, 1967 e 1988) e dois golpes de estado (1937 e 1964) ajudaram a conformar o modelo de "federalismo fiscal à brasileira" 9 (p. 512), vigente no país.

A reforma fiscal de 1967, ainda que mantivesse a concentração da arrecadação no nível federal, ampliou a capacidade de arrecadação de estados (Imposto sobre Circulação de Mercadorias e Prestação de Serviços - ICMS) e municípios (Imposto sobre Serviços de Qualquer Natureza - ISS) e definiu mecanismos de redistribuição e devolução a estas instâncias, aumentando sua capacidade de gasto. Durante os anos mais rígidos da ditadura prevaleceu a centralização de arrecadação e gastos, a qual, gradual e concomitantemente com o processo de abertura política, vai se diluindo e se conformando no modelo pactuado em 1988. O federalismo fiscal normalizado pela Constituição de 1988 reproduziu preceitos introduzidos por aquela de 1967, buscando ajustá-los a uma realidade totalmente distinta, fato que tem sido responsabilizado por vários conflitos entre os entes federativos 10 , conflitos estes que se espraiam também para questões relativas ao financiamento público da saúde.

Pela Constituição de 1988, o financiamento do SUS foi definido como competência comum da União, estados, Distrito Federal e municípios, mediante recursos do Orçamento da Seguridade Social (OSS) e do orçamento fiscal daqueles entes federados (Constituição Federal de 1988; Art. 198). Assim, como já ocorria anteriormente, o financiamento da saúde se apóia em orçamentos fiscais e de contribuições.

O OSS - composto por contribuições sociais de empregadores e trabalhadores, de outras receitas e também de parte de recursos da União, de estados e municípios - deveria financiar a previdência, a assistência social e parte significa- 
tiva da assistência à saúde. Até meados dos anos 1990, uma parcela do OSS próxima a 30\%, definida constitucionalmente (ADCT) ou por Lei de Diretrizes Orçamentárias (LDO), foi alocada em saúde, ainda que sob tal rubrica se incluíssem despesas com saneamento, merenda escolar e encargos previdenciários, entre outras 11. Como o OSS, contínua e gradualmente tem sido mais utilizado para o financiamento da previdência social, outros arranjos e alternativas foram adotados, a partir de meados da década de 1990, principalmente vinculando à saúde recursos de novas contribuições ou de parcela do orçamento fiscal dos entes federativos 12. No primeiro caso sobressai-se a Contribuição Provisória sobre a Movimentação ou Transmissão de Valores e de Créditos e Direitos de Natureza Financeira (CPMF), que vigorou até dezembro de 2007, como imposto na sua implantação (1994) e logo depois como contribuição; e no segundo, a Emenda Constitucional no. 29 (EC-29) 13.

Discutida desde os anos 1990 e aprovada somente em 2000, como forma de assegurar os recursos mínimos para financiamento de ações e serviços de saúde, a EC-29 manteve a base de financiamento regulamentada na Constituição e definiu a obrigatoriedade, por parte da União, dos estados, do Distrito Federal e dos municípios, de aplicação de recursos cujos percentuais mínimos seriam regulamentados por lei complementar. Em 2003, o Conselho Nacional de Saúde, visando a prover maior esclarecimento sobre tal assunto, aprova a Resolução $n^{o} .322$ 14, a qual consolida e dá mais clareza sobre a aplicação da EC-29 enquanto tramita no Congresso Nacional o projeto de lei regulamentando parágrafos específicos e importantes desta emenda.

O Projeto de Lei Complementar $n^{\circ}$. 121/07, originado no Senado, foi por este aprovado em maio de 2008 e encontra-se em tramitação na Câmara de Deputados, agora como Projeto de Lei Complementar $n^{o}$. 306/08. Nesse, tendo em vista a extinção da CPMF, foi incorporado um substitutivo que cria a Contribuição Social para a Saúde (CSS), com alíquota de $0,1 \%$ sobre qualquer movimentação financeira, cuja arrecadação fica totalmente vinculada ao custeio de despesas na área da saúde.

Ainda que percentuais baixos do OSS sejam destinados ao setor saúde 12 , as contribuições sociais têm representado mais de $70 \%$ dos recursos do Ministério da Saúde ${ }^{3}$. Dessa forma, o que está institucionalizado no Brasil é que o financiamento público da saúde se dá pelo OSS e, em maior percentual, por parcelas das receitas da União, dos estados (e Distrito Federal) e dos municípios, receitas estas que conformam os orçamentos fiscais destes entes federativos.
Muitos são os trabalhos que buscam analisar o financiamento da saúde no Brasil, quase sempre abordando, de forma agregada, os três níveis da federação 15,16,17,18,19,20. Embora se reconheça a enorme heterogeneidade de estados e municípios brasileiros e a particularidade dos gastos com saúde nestas unidades, ainda são poucos os estudos que abordam este tema em contextos regionais ou de estados/municípios específicos, salientando-se aqui os recentes trabalhos de Viana et al. 21, Fortes et al. 22 e Mendes et al. ${ }^{23}$. Assim, o presente trabalho busca analisar a sustentabilidade financeira e econômica dos gastos públicos em saúde, no nível local do Estado de Mato Grosso, com base nas receitas correntes que compõem os orçamentos municipais, e mais especificamente, os "orçamentos-base da EC-29".

\section{Material e método}

O Estado de Mato Grosso, segundo a contagem populacional de 2007, tem uma população de 2.854.642 habitantes, distribuída em 141 municípios, a maioria com menos de 20 mil habitantes (81\%) e em Gestão Plena da Atenção Básica - GPAB (93,6\%). No que tange ao setor saúde, os municípios mato-grossenses estão organizados em 16 Escritórios Regionais de Saúde e 14 Microrregiões de Saúde 24 .

O presente estudo contemplou 21 municípios de diferentes: porte, localização geográfica, nível sócio-econômico (Índice de Desenvolvimento Humano - IDH) e forma de gestão. A seleção desses municípios não foi aleatória, mas buscou-se, com base naquelas quatro categorias, contemplar a diversidade de situações existentes no estado 25 .

Os municípios de estudo representavam, em 2007: $15 \%$ do total de municípios e 56,8\% da população do estado; $66,7 \%$ dos nove municípios em Gestão Plena do Sistema Municipal (GPSM) e 11,4\% dos 132 municípios em GPAB. Representavam também 10 (71,4\%) microrregiões e 10 (62,5\%) Escritórios Regionais de Saúde. A amostra contemplou o universo de municípios grandes ( $\geq 50$ mil habitantes), inclusive a capital; $40 \%$ dos de porte médio (entre 20 mil e 49.999 habitantes); e $6 \%$ dos municípios pequenos $(<20$ mil habitantes).

Nesse recorte, priorizou-se a agregação segundo porte populacional, tendo em vista que tanto a arrecadação como as transferências de recursos estão relacionadas ao tamanho da população dessas unidades.

O levantamento de dados compreendeu o período de 1995 a 2006, abarcando fundamen- 
talmente as receitas correntes anuais, coletadas de cada um dos municípios estudados, de modo a evidenciar as fontes e origens de tais recursos, conforme prevê a Constituição e as normalizações referentes à EC-29. A Figura 1 esquematiza a composição do orçamento municipal no que tange às receitas correntes.

a) Receitas correntes municipais (M), compostas por: uma parcela de recursos arrecadados pelo município, na forma de impostos municipais (Imposto Predial e Territorial - IPTU, ISS, Imposto sobre Transmissão de Bens Imóveis - ITBI, Imposto de Renda Retido na Fonte-IRRF) e de multas, juros e dívida ativa (relativos àqueles impostos), aqui nomeada de "receitas municipais vinculadas à EC-29” (m); parcela complementar de recursos arrecadados pelo município, na forma de taxas, outras receitas (patrimoniais, agropecuárias, industriais, de contribuições e de serviços), bem como multas, juros e dívida ativa (relativos a estas arrecadações), aqui nomeada de "receitas municipais não vinculadas à EC-29” (m'). b) Transferências do estado (E), compostas por: recursos arrecadados pelo estado, na forma de impostos (ICMS, Imposto sobre a Propriedade de Veículos Automotores - IPVA, Imposto sobre Produtos Industrializados - IPI), e que são transferidos aos municípios, aqui nomeados de "transferências constitucionais do estado vinculadas à EC-29” (e); todas as demais receitas correntes transferidas pelo estado, nomeadas de "transferências do estado não vinculadas à EC-29” (e').

c) Transferências da União (U), compostas por: recursos arrecadados pela União, na forma de impostos (Fundo de Participação dos Municípios das Capitais - FPM, Imposto Territorial Rural - ITR, Lei $n^{\circ}$. 86/96), aqui nomeados de "transferências constitucionais da União vinculadas à EC-29" (u); todas as demais receitas correntes transferidas pela União, nomeadas de "transferências da União não vinculadas à EC-29” (u').

A soma das receitas identificadas como " $\mathrm{m}$ ", "e" e "u" é chamada de "orçamento-base da EC-29”, uma vez que constitui o denominador (ou base de cálculo) para o percentual de recursos que cada município deve aplicar em saúde, segundo a EC-29. A sustentabilidade de que trata $o$ artigo refere-se basicamente ao comportamento dessa fração do orçamento municipal, dado que a contrapartida municipal para a saúde depende da evolução do volume desses recursos, por ser um percentual dele.

Como fontes de dados de receitas correntes foram utilizados: (a) balanços municipais, referentes a 1995-1998, consultados nas Secretarias de Finanças/Planejamento e/ou Câmaras Municipais de Vereadores dos municípios do estudo 25; (b) balanços municipais consultados no Tribunal de Contas do Estado, relativos a 1999, e planilhas preenchidas por técnicos deste órgão, relativas aos balanços de 2000; (c) planilhas de

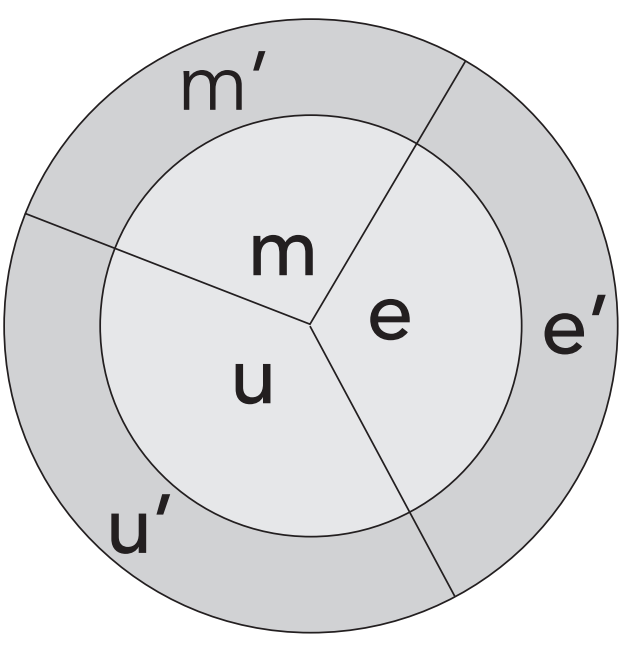

Receitas municipais $\left(M=m+m^{\prime}\right)$

$\mathrm{m}=$ receitas municipais referentes à $E$ e Co st t co 10.29

(EC-29);

$\mathrm{m}^{\prime}=$ receitas municipais não referentes à EC-29.

Transferências do estado ( $\left.E=e+e^{\prime}\right)$

$\mathrm{e}=$ transferências constitucionais do estado referentes à EC-29,

$\mathrm{e}^{\prime}=$ transferências do estado não referentes à EC-29.

Transferências da União $\left(U=u+u^{\prime}\right)$

$\mathrm{u}=$ transferências constitucionais da União referentes à EC-29;

$\mathrm{e}^{\prime}=$ transferências da União não referentes à EC-29.

Orçamento-base para a EC-29 $=m+e+u$ 
receitas da administração direta e indireta providas pelo SIOPS, relativas ao período 2000-2006. Para os dados populacionais, a principal fonte foi o Instituto Brasileiro de Geografia e Estatística (IBGE), cujos dados censitários, de contagem e de estimativas foram extraídos da página eletrônica do Departamento de Informática do SUS (DATASUS; http://www.datasus.gov). Em relação à inflação, utilizou-se o Índice Nacional de Preços ao Consumidor Amplo (IPCA), provido pelo IBGE. Os dados sobre Produto Interno Bruto (PIB) foram extraídos da página eletrônica do Instituto de Pesquisa Econômica Aplicada (IPEA; http://www.ipea.gov.br).

Embora se pretendesse iniciar a análise a partir do ano de 1995, constatou-se naquele ano: elevada inflação, ausência de dados de alguns municípios e muitos dados discrepantes. Assim, optou-se por redefinir como período de estudo o interstício entre 1996 e 2006, o qual compreende parte do período de vigência, no estado, da Norma Operacional Básica (NOB-93; 1996 a 1998); o período de vigência da NOB-96, distinto para alguns municípios (1998 a 2002/2006); e o período de vigência da Norma Operacional da Assistência à Saúde (NOAS-2002; 2002 a 2006).

Para tal análise, as receitas correntes foram transformadas em valores per capita, que constituíram indicadores passíveis de comparação entre os distintos agrupamentos de municípios. A evolução desses indicadores foi analisada tendo como parâmetro as normas que regulamentam as contrapartidas financeiras para a saúde: a EC-29, Resolução CNS no $n^{\circ}$ 322/03 e o Projeto de Lei Complementar $n^{\circ}$. 306/08. Na análise dos dados considerou-se ainda a evolução do desempenho econômico do país (em termos de PIB), dado que tal desempenho é fator determinante da arrecadação, a qual gera as receitas nas quatro esferas de governo; e também o comportamento da inflação, que compromete o "valor" destas receitas.

O presente trabalho é um recorte de uma pesquisa mais ampla, Descentralização e Financiamento da Saúde no Estado de Mato Grosso, aprovada por dois Comitês de Ética em Pesquisa: Comissão de Ética para Análise de Projetos de Pesquisa do Hospital das Clínicas e da Faculdade de Medicina da Universidade de São Paulo (protocolo no. 0848/07), e Comitê de Ética em Pesquisa da Secretaria de Estado de Saúde de Mato Grosso (protocolo $\mathrm{n}^{\circ}$. 336/07).

\section{Resultados}

A composição dos orçamentos gerais dos municípios variou bastante, conforme seu porte, principalmente no que tange à arrecadação própria (M) e às transferências da união (U). Em média, nos 11 anos estudados, as transferências estaduais (E) representaram os maiores percentuais dos orçamentos, muito próximos nos quatro conjuntos de municípios (Figura 2). As duas outras fontes completaram os orçamentos municipais numa dinâmica própria: as receitas municipais tiveram baixo peso percentual nos municípios pequenos e foram crescendo à medida que aumentou o porte - e a capacidade de arrecadação - destas unidades, atingindo quase 1/3 do orçamento da capital; de forma inversa e complementar, as transferências federais representaram percentuais elevados nos municípios pequenos e decresceram até os 29,3\% observados em Cuiabá, Mato Grosso.

Entre 1996 e 2006 as receitas correntes gerais per capita elevaram-se muito além da inflação acumulada no período (Figura 3). Comparandose os dois anos extremos, a elevação foi de $330,7 \%$ na capital e $293,9 \%, 266,8 \%, 247,2 \%$, respectivamente, no conjunto dos municípios grandes, médios e pequenos. Há variações na magnitude dos valores, segundo o porte dos municípios, mas o comportamento das curvas é semelhante. Quando se incorpora à Figura 3 o PIB nacional per capita, observa-se que a evolução das despesas correntes, principalmente dos municípios médios e grandes, reproduz, respeitada a escala, a evolução do PIB. Enquanto de 1996 a 2001 a elevação das receitas correntes é menos acentuada (exceção feita a Cuiabá), entre 2001 e 2006 a ascensão das quatro curvas é maior.

A evolução das receitas municipais (M), per capita, reproduz a tendência observada na Figura 3, mas com mudanças na ordem dos municípios, segundo porte. $\mathrm{O}$ aumento observado foi superior ao da inflação, para todos os municípios. Pelos valores anuais, sobressaíram-se Cuiabá e os municípios maiores, nos quais se observou maior capacidade de arrecadação em relação ao conjunto de municípios de porte médio e pequeno. As receitas correntes municipais também acompanharam, em média, a evolução do PIB e, à semelhança do comportamento das receitas correntes gerais, a elevação entre 2001 e 2006 também foi mais acentuada que a do período anterior.

A evolução das receitas que compõem o orçamento-base da EC-29, em nível municipal, revela que houve um aumento importante no volume de tais recursos, ultrapassando em mais de 70\% a inflação no período (Figura 4). De 1996 
2a) Pequenos

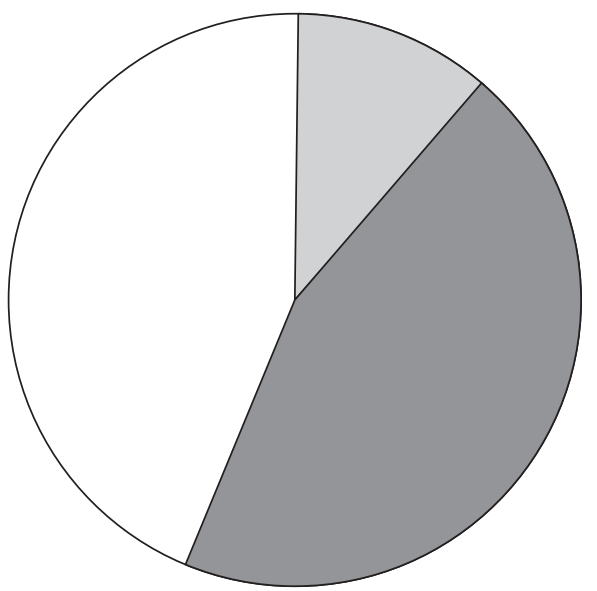

2c) Grandes

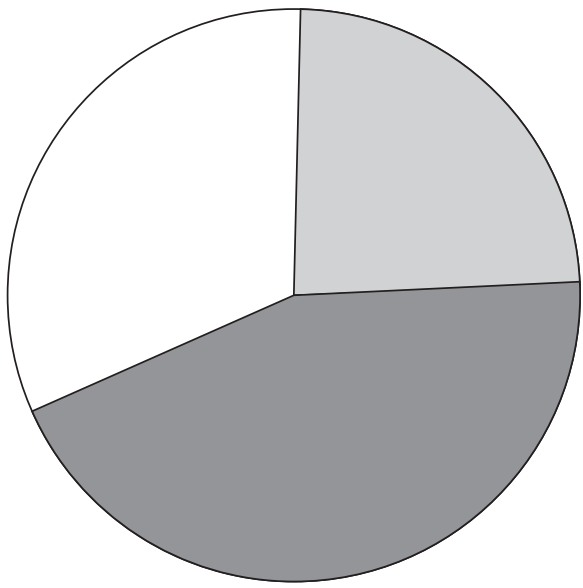

\section{2b) Médios}
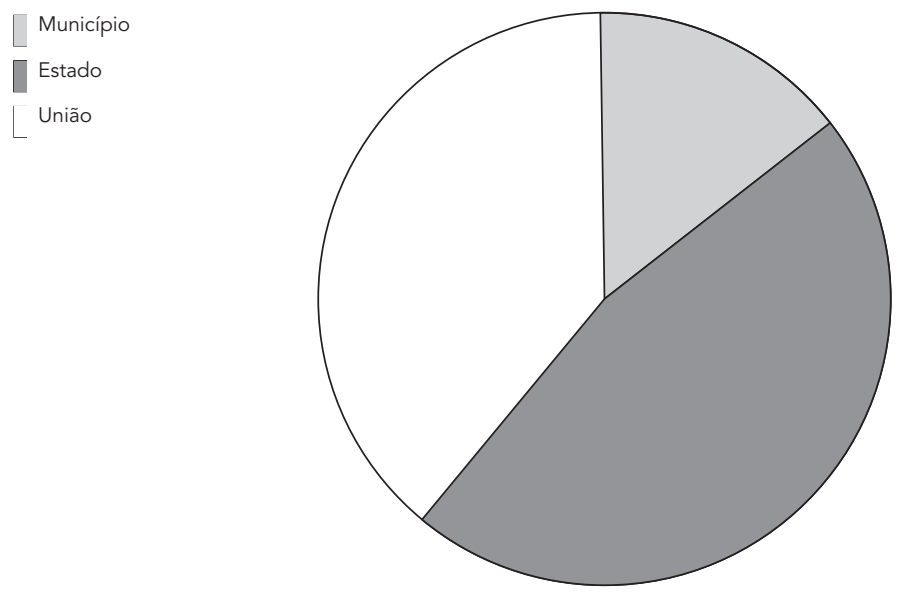

|| Município

Estado

$\square$ União 2d) Capital

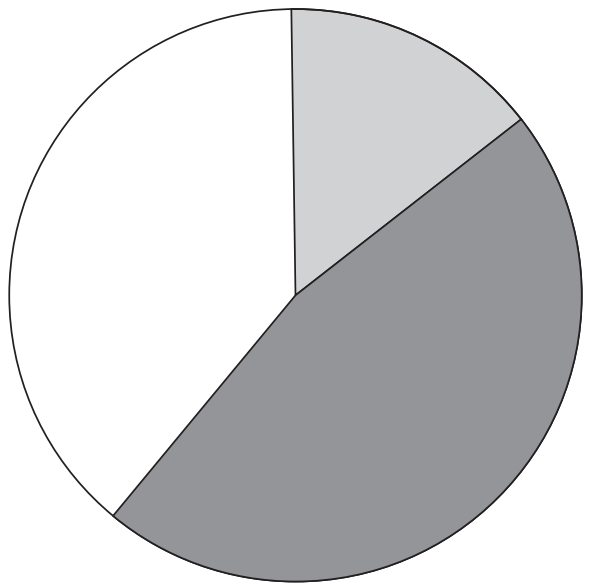

Município

Estado $\prod$ União a 2006, esse orçamento elevou-se de forma muito parecida no conjunto de municípios pequenos (166,1\%), médios (183,9\%), grandes $(190,4 \%)$ e mesmo na capital $(179,4 \%)$. Comparando-se essas curvas com a do PIB nacional, destaca-se a evolução do orçamento-base da EC-29 dos municípios pequenos, tanto pela magnitude dos valores como pelo aumento percentual acima do PIB, entre 2001 e 2005.

Ao compararmos a evolução das receitas correntes gerais e do orçamento-base da EC-29, ob- servou-se que, de 1996 a 2006, o incremento das primeiras foi maior (247\% a 330\%) e diretamente proporcional ao porte dos municípios (Figura 5). Por outro lado, o incremento do orçamento-base foi menor e manteve-se num mesmo patamar (entre $166 \%$ e 190\%), independente do porte dos municípios.

Assim, embora em valores per capita o orçamento-base da EC-29 tenha se elevado, como evidenciado na Figura 4, seu peso percentual, em relação às receitas gerais, vem reduzindo gradu- 
Figura 3

Receitas correntes gerais por habitante (em R\$). Municípios de Mato Grosso, Brasil, 1996 a 2006.

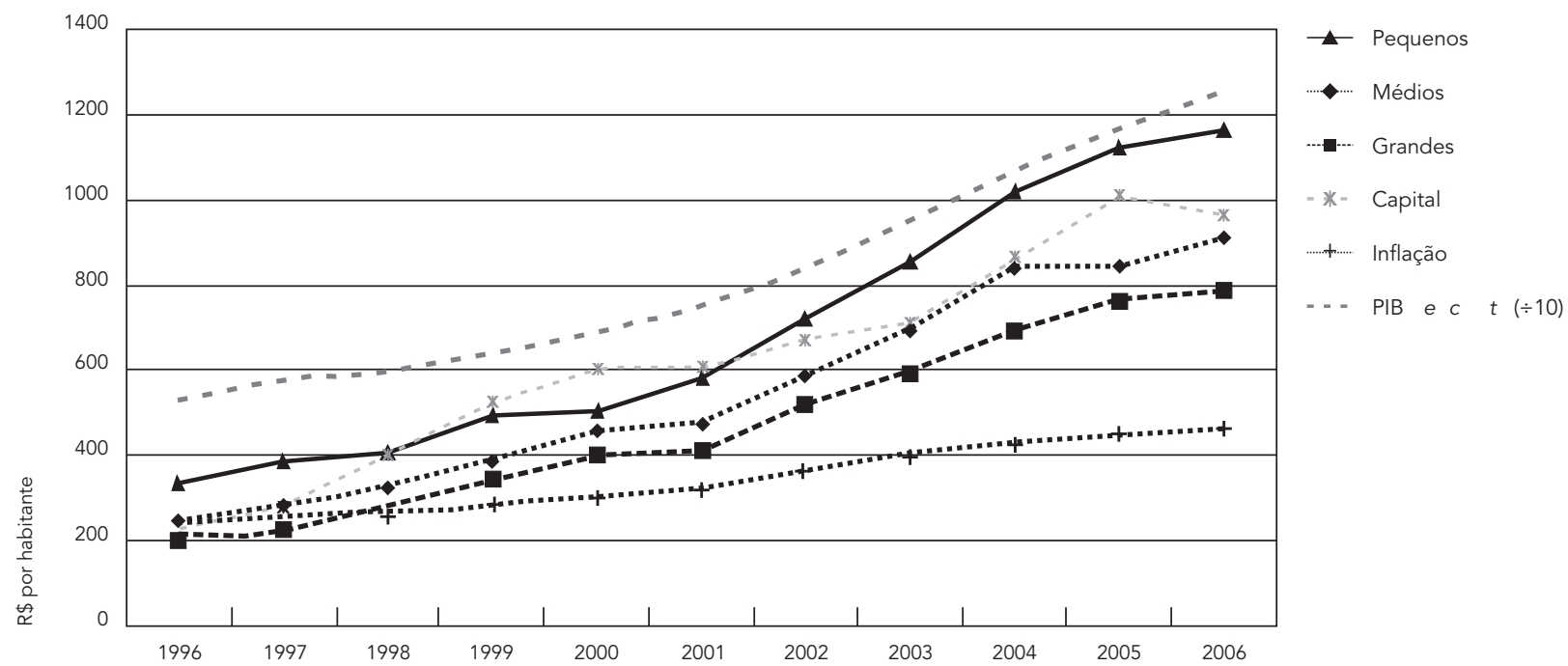

Figura 4

Receitas correntes por habitante (em R\$), que compõem o orçamento-base da Emenda Constitucional nº. 29 (EC-29). Municípios de Mato Grosso, Brasil, 1996 a 2006.

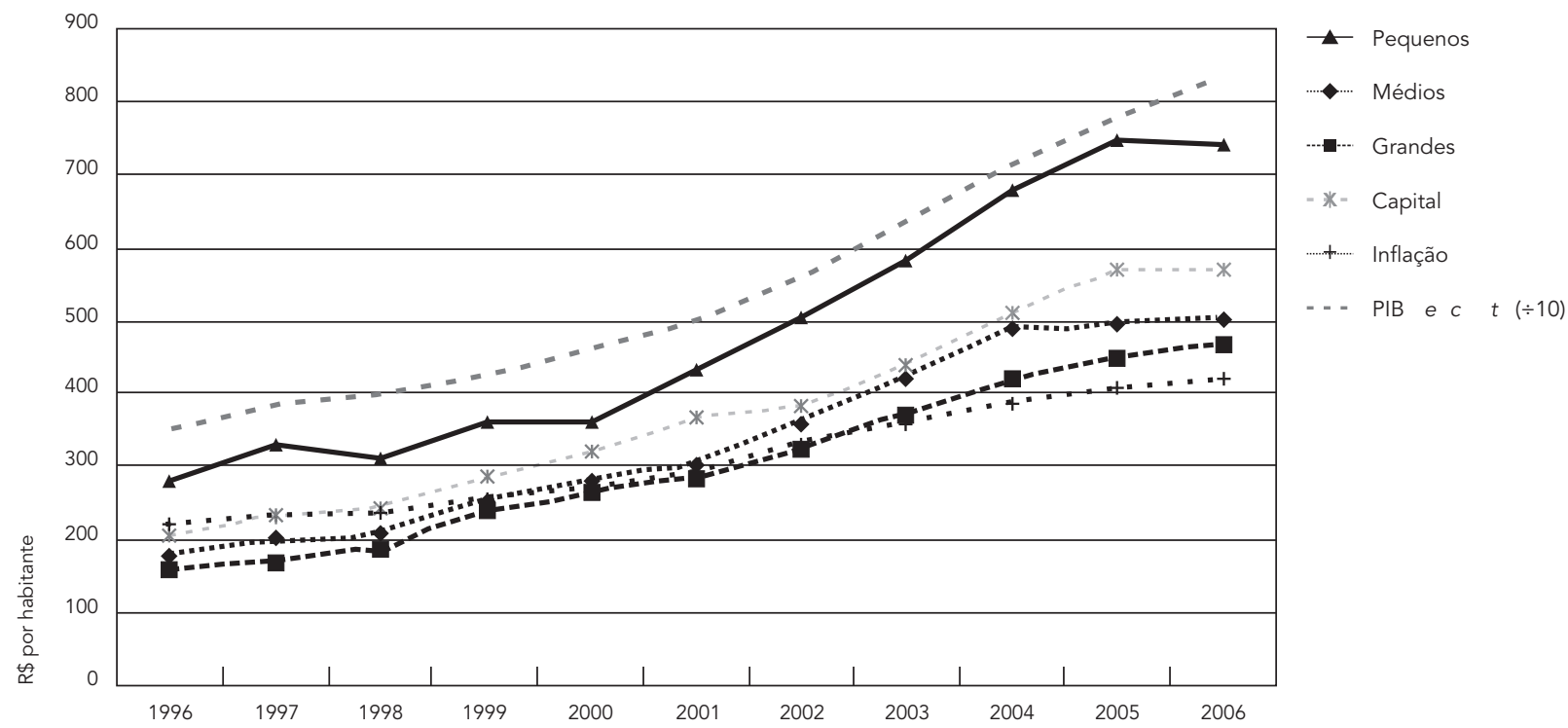


Variação percentual das receitas correntes gerais e do orçamento-base da Emenda Constitucional nº. 29 (EC-29), per capita. Municípios de Mato Grosso, Brasil, 1996 a 2006.

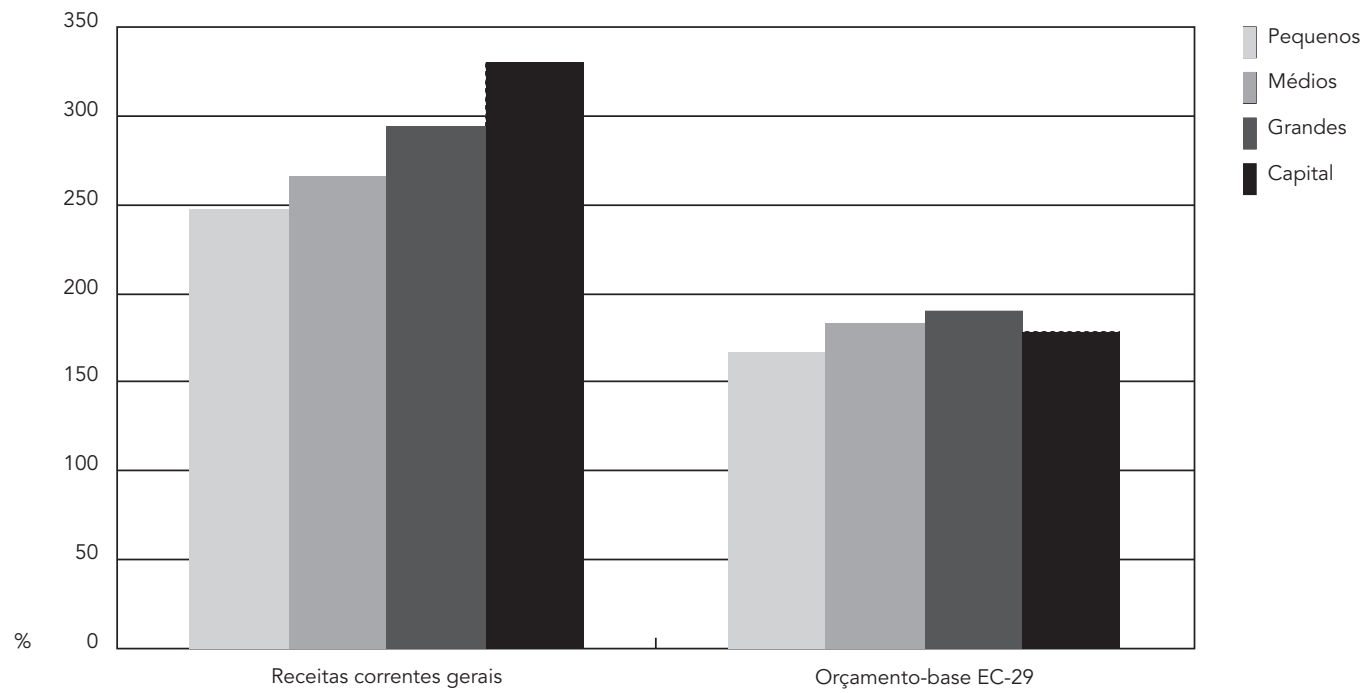

almente (Figura 6). A maior redução foi observada em Cuiabá $(35,1 \%)$, enquanto nos outros três conjuntos de municípios tal queda ficou próxima dos $20 \%$. Se em 1996, na média e na maioria dos municípios, os orçamentos-base para a EC-29 representavam $80 \%$ do total de receitas correntes, em 2006 eles passam a representar 60\% destas receitas.

\section{Discussão}

O PIB, que é dado pela soma de todos os bens e serviços produzidos, é um dos indicadores macroeconômicos mais utilizados na mensuração da atividade econômica de um país (ou região), estado ou município 26 . A evolução do PIB nacional per capita entre 1996 e 2006 conforma uma curva ascendente que pode ser decomposta em dois segmentos, de inclinações distintas. $\mathrm{O}$ primeiro, de 1996-2001, tem menor angulação e reflete um crescimento de $43,2 \%$ entre estes dois anos. Já o segundo segmento, de 2001 a 2006, tem inclinação bem mais acentuada, e a variação entre os anos extremos é de $66,7 \%$. Se no primeiro segmento da curva, PIB e inflação acumulada evoluem de forma muito semelhante, no segundo, principalmente após 2002, o crescimento do PIB é bem superior ao da inflação, refletindo o desempenho mais pujante da economia brasileira nesse período.

É de se esperar que o comportamento da economia nacional repercuta e se reproduza nos orçamentos da União, dos estados, do Distrito Federal e dos municípios, dadas as características do sistema de arrecadação e redistribuição tributária vigente.

Sobre a carga tributária bruta brasileira, Santos et al. 27 apontam sua elevação, entre 1995 e 2007, período em que passou de $26 \%$ a $35,6 \%$ do PIB. Os autores identificam também dois momentos distintos nesse período, quase coincidentes com aqueles acima mencionados. Num primeiro momento, de 1995 a 2003, a elevação seria decorrente de maior tributação sobre empresas estatais, criação de novos impostos e/ou aumento de alíquotas de impostos existentes. Já a partir de 2004, a elevação seria decorrente do aumento da lucratividade das empresas e da formalização da economia, "associados a um novo (e ainda pouco compreendido) ciclo de crescimento econômico".

No Estado de Mato Grosso, as receitas correntes gerais (per capita) dos municípios estudados elevaram-se globalmente, tanto na fração arrecadada localmente quanto nas frações redistribuídas por estado e União. Tal elevação, além de superar a inflação acumulada, ultrapassou 


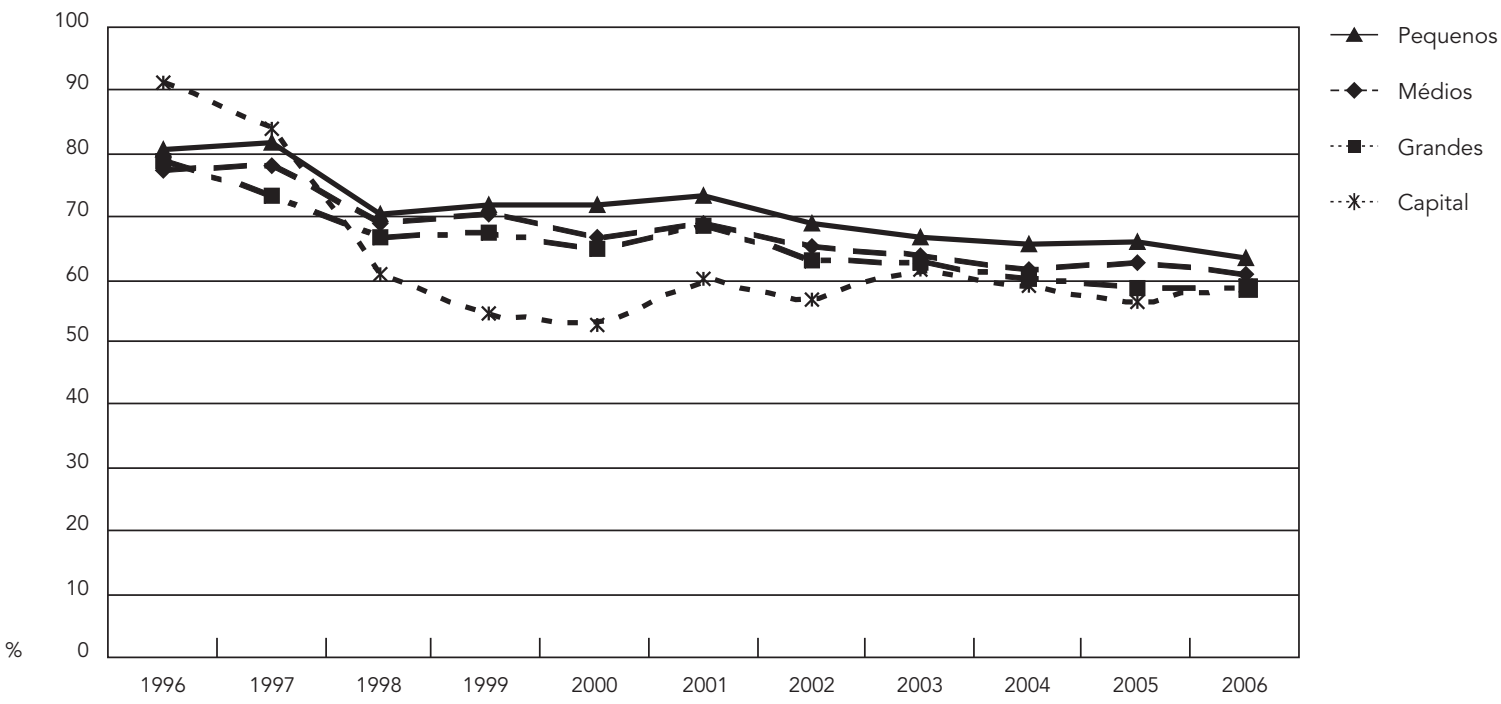

aquela do PIB per capita. Como as receitas correntes são compostas basicamente de tributos (impostos, taxas e contribuições), o aumento do peso percentual da carga tributária em relação ao PIB - por maior tributação, lucratividade ou formalização da economia - explicaria o fato de as receitas correntes gerais terem tido um incremento maior que o do PIB, entre 1996 e 2006.

O que chama a atenção, no conjunto de dados apresentados, é o fato de os recursos financeiros que compõem a base para o cálculo da EC-29 terem se reduzido, proporcionalmente, em relação às receitas correntes gerais. Como o orçamento-base para a EC-29 é parte das receitas correntes e estas se elevaram mais que aquele, a redução percentual observada é uma conseqüência lógica (aritmética) da conjunção destes dois fatores. O importante é buscar entender o que está fomentando essa situação e identificar suas eventuais repercussões no financiamento da saúde, em nível municipal.

No que tange à fração do orçamento que é gerada por arrecadação municipal (M), tanto as receitas que compõem o orçamento-base da EC-29 (m) quanto aquelas que não o compõem (m') elevaram-se em percentuais muito próximos. Já em relação às transferências da União e estado $(U+E)$, aquelas parcelas identificadas como transferências constitucionais vinculadas à EC-29, da União e do estado (u + e), e que entram na composição do orçamento-base da EC-29 no município, elevaram-se aquém das demais transferências federais e estaduais $\left(u^{\prime}+e^{\prime}\right)$, que não compõem o orçamento-base da EC-29. Entre essas últimas, encontram-se aquelas "vinculadas” a políticas e/ou ações específicas, em que sobressaíram os recursos para o SUS, Fundo de Manutenção e Desenvolvimento do Ensino Fundamental e de Valorização do Magistério (FUNDEF), Fundo Nacional de Desenvolvimento da Educação (FNDE), e em menor volume, para convênios não especificados.

As transferências de estado e União para a saúde, além de não entrarem na base de cálculo do orçamento para a EC-29, tiveram incremento importante e têm representado, no Brasil, aproximadamente metade dos recursos despendidos no setor saúde, em nível municipal ${ }^{3}$. No Estado de Mato Grosso, o SIOPS informa que essas transferências representaram, em média, 46,3\% do volume de recursos aplicados em saúde, no conjunto dos municípios, de 2000 a 2007 (http:/ / www.datasus.gov.br/CGI/deftohtm.exe?SIOPS/ serhist/municipio/indicMT.def, acessado em 23/Fev/2009). Portanto, praticamente metade dos recursos que são investidos em saúde, em nível municipal, não depende do comportamento do orçamento-base da EC-29, dado que provém de transferências específicas de estado e União, e não faz parte daquele orçamento. 
Ressalta-se que os recursos municipais para a saúde elevaram-se nos últimos anos como decorrência da EC-29 e, no caso dos municípios do Estado de Mato Grosso, a média de gastos próprios com ações e serviços públicos de saúde, segundo dados do SIOPS (http://www.datasus. gov.br/CGI/deftohtm.exe?SIOPS/serhist/muni cipio/indicMT.def, acessado em 23/Fev/2009), tem sido superior a $19 \%$ do orçamento-base da EC-29 desde 2005, ou seja, superando o patamar mínimo de $15 \%$ estabelecido pela EC-29 para a contrapartida municipal destinada à saúde.

Para manter a evolução dos investimentos em saúde no nível crescente dos últimos seis anos, ou em consonância com o crescimento das receitas correntes gerais, os gestores municipais têm duas opções: (1) aumentar a contrapartida municipal em saúde para além daquele percentual mínimo regulamentado pela EC-29; (2) utilizar em saúde parcela do orçamento municipal que não compõe a base de cálculo da EC-29. Como essa última alternativa configura-se em irregularidade, quando aplicada às transferências “vinculadas” da União (u') e estados (e'), e é pequena a parcela dos recursos exclusivamente municipais que não compõem a base de cálculo para a EC-29 (m'), resta aos municípios a adoção da primeira alternativa.

Os recursos que compõem o orçamento-base da EC-29 são aqueles sobre os quais os municípios têm autonomia, muito próximos daquilo que Mendes 28 nomeia de "receitas disponíveis". São recursos "não vinculados", cuja aplicação, em princípio, é definida a partir dos problemas, das necessidades e da realidade de cada município; e das alternativas (ou políticas) adotadas frente a eles. Ao ter de alocar, em ações e serviços de saúde, percentuais cada vez mais elevados de suas receitas, os municípios podem comprometer outros setores, ou mesmo fomentar conflitos internos entre os vários atores da administração municipal. Isso pode gerar obstáculos à governabilidade municipal, com conseqüências negativas inclusive ao próprio setor saúde, que, por sua natureza, tem interfaces múltiplas com os demais setores.

\section{Considerações finais}

O que se buscou colocar em discussão, neste texto, foi a sustentabilidade daqueles gastos com saúde realizados pelos municípios, a partir de seus orçamentos-base da EC-29, dos quais estão excluídas, entre outras, as transferências especificas para a saúde, feitas por União e estado. No entanto, há que se pontuar minimamente quatro "fatos novos" (já ocorridos, em curso ou previstos) que devem interferir no cenário que se descortina para o financiamento público da saúde, e agora não restrito apenas à contrapartida municipal: (1) a extinção da CPMF, em dezembro de 2007; (2) a regulamentação da EC-29, atualmente mediante o Projeto de Lei Complementar $n^{\circ}$. 306/08, em tramitação na Câmara dos Deputados; (3) a iminência de uma recessão, a partir da crise do sistema financeiro norte-americano, que rapidamente se espalhou para países centrais e países emergentes; (4) a proposta de reforma fiscal em curso.

Ainda que os recursos repassados ao Ministério da Saúde representem parcela minoritária do montante das contribuições sociais, estas ainda são a principal fonte de financiamento deste Ministério (média de 77\%, de 1997 a 2005) ${ }^{3}$. Dentre as contribuições sociais, a CPMF sempre teve papel importante para a saúde, representando praticamente $30 \%$ dos recursos alocados no setor, em nível federal. No caso dos municípios mato-grossenses, e provavelmente na maioria dos municípios brasileiros, pode-se dizer que, na sua vigência, a CPMF viabilizou entre $10 \%$ e $20 \%$ dos gastos públicos com saúde, uma vez que as transferências federais representaram entre 30\% e $65 \%$ dos gastos com saúde realizados nos municípios. Assim, vislumbra-se um cenário pouco favorável para o setor, caso a perda da CPMF não seja absorvida, quer por rearranjo das fontes de financiamento federal, quer por criação de contribuição substitutiva, como seria o caso da polêmica CSS, constante do substitutivo ao Projeto de Lei Complementar $n^{\circ}$. 306/08.

Esse projeto de lei define que devam ser aplicados em ações e serviços de saúde, minimamente: (1) pela União - 10\% de suas receitas correntes brutas, percentual a ser integralizado até 2011, evoluindo de $8,5 \%$ a $9 \%$ e 9,5\%, respectivamente, de 2008 a 2009 e 2010; (2) pelos estados - 12\% da soma da arrecadação de impostos estaduais e das transferências constitucionais da União, excluídas as transferências legais aos municípios; (3) pelos municípios - 15\% da soma da arrecadação de impostos municipais e das transferências constitucionais, da União e respectivos estados. O que esse projeto de lei muda, em relação à EC-29, é a definição da parcela da União como percentual das receitas correntes brutas. O que aquelas normas preconizam, a cada ano, é a aplicação do montante empenhado pela União em saúde, no ano imediatamente anterior, corrigido pela variação nominal do PIB do ano em que se elabora a proposta orçamentária. Resta saber se quando o Projeto de Lei Complementar $n^{\circ}$. 306/08 for aprovado, os percentuais ali definidos, para a União, equivalerão ou não ao montante que ora vem sendo aplicado. 
A crise do sistema financeiro, que iniciada nos Estados Unidos, se espraia rapidamente para todo o mundo, em diferentes intensidade e ritmo, é um acontecimento cujas repercussões são ainda nebulosas, contraditórias e de difícil previsão. Há, no entanto, certo consenso de que haverá uma desaceleração do crescimento econômico nos países emergentes e conseqüente diminuição da arrecadação. No Brasil, isso significa um comprometimento dos orçamentos dos quatro entes federativos, com implicações para o setor saúde, que no nível municipal podem se dar por duas vias: redução ou desaceleração dos investimentos próprios, vinculados ao orçamento-base para a EC-29; e redução de transferências federais e estaduais, específicas para a saúde.

É sabido que o sistema tributário no Brasil não é justo nem progressivo conforme a renda 4,29 .
No entanto, a reforma tributária, em tramitação no Congresso Nacional como Proposta de Emenda Constitucional $n^{\circ}$. 233/08, na forma em que se apresenta não corrige desigualdades históricas e comprometerá sensivelmente o financiamento das políticas sociais ${ }^{30}$. Não é objetivo deste trabalho discutir tal assunto, até porque, na conjuntura político-econômica atual, é provável que tal Proposta de Emenda Constitucional permaneça ainda muito tempo "em tramitação" no legislativo. No entanto, é importante que esse e os demais fatos aqui apontados sejam considerados, também nas pesquisas, mas principalmente em processos de planejamento e programação feitos pelos gestores de saúde, independente do nível em que atuam.

\section{Resumo}

O financiamento do SUS é regido pelo modelo de federalismo fiscal, pelas regras de partilha do Orçamento da Seguridade Social (OSS), por normas do Ministério da Saúde, e pela Emenda Constitucional no. 29 (EC-29), que vincula à saúde recursos dos entes federados brasileiros. Discute-se aqui a sustentabilidade do gasto público com saúde no nível municipal. Foram estudados 21 municípios, utilizando-se dados dos balanços municipais. De 1996 a 2006 as receitas correntes gerais per capita subiram 280\% acima da inflação acumulada e do Produto Interno Bruto (PIB) nacional, variando conforme o porte do município, o qual também definiu a composição dos orçamentos municipais. Já o orçamento que conforma a base da EC-29 elevou-se bem menos (178\%), impondo limita- ções ao incremento da contrapartida municipal em saúde. Acredita-se que o observado nesses municípios se reproduza em milhares de municípios brasileiros e comprometa a capacidade de investimento municipal em saúde, principalmente a partir de 2008. A situação ainda pode se agravar tendo em vista a extinção da Contribuição Provisória sobre a Movimentação ou Transmissão de Valores e de Créditos e Direitos de Natureza Financeira (CPMF), a tramitação dos Projetos de Lei $n^{\circ} .306 / 08$ e $\mathrm{n}^{\circ}$. 233/08, e a recessão mundial, a partir da crise do sistema financeiro norte-americano.

Sistema Único de Saúde; Financiamento em Saúde; Gastos em Saúde; Descentralização 


\section{Colaboradores}

J. H. G. Scatena concebeu o trabalho, coletou os dados e participou da redação, discussão e revisão do texto. A. L. d'A. Viana e O. Y. Tanaka participaram do recorte e redimensionamento do trabalho, da redação, discussão e revisão do texto.

\section{Agradecimentos}

Os autores agradecem ao Conselho Nacional de Desenvolvimento Científico e Tecnológico (CNPq) pela concessão de bolsa de pós-doutorado a J. H. G. Scatena, um dos elementos viabilizadores deste trabalho.

\section{Referências}

1. Scatena JHG, Tanaka OY. Distribuição dos estabelecimentos de saúde no Brasil: para qual modelo caminhamos? Rev Adm Pública 1988; 32:7-25.

2. Pinto MBF, Gonçalves MF, Neves MGR. Pensando a autonomia municipal: dilemas e perspectivas. Revista de Administração Municipal - Municípios 2003; 48(Encarte especial):1-8.

3. Conselho Nacional de Secretários de Saúde. O financiamento da Saúde. Brasília: Conselho Nacional de Secretários de Saúde; 2007. (Coleção Progestores - Para Entender a Gestão do SUS, 3).

4. Ugá MAD, Santos ISS. Uma análise da progressividade do financiamento do Sistema Único de Saúde (SUS). Cad Saúde Pública 2006; 22:1597-609.

5. Instituto Brasileiro de Geografia e Estatística. Economia da saúde: uma perspectiva macroeconômica 2000-2005. Rio de Janeiro: Instituto Brasileiro de Geografia e Estatística; 2008.

6. Teixeira HV, Teixeira MG. Financiamento da saúde pública no Brasil: a experiência do SIOPS. Ciênc Saúde Coletiva 2003; 8:379-91.

7. Mascarenhas RS. Financiamento dos serviços de saúde pública. Rev Saúde Pública 2006; 40:559-72.

8. Afonso JR, Meirelles BB, Castro KP. A verdadeira carga pesada: tributação no brasil. Rio de Janeiro: Prefeitura Municipal do Rio de Janeiro; 2006. (Estudos, 207).
9. Lima LD. Conexões entre o federalismo fiscal e o financiamento da política de saúde no Brasil. Ciênc Saúde Coletiva 2007; 12:501-22.

10. Lima LD. Federalismo, relações fiscais e financiamento do Sistema Único de Saúde: a distribuição de receitas vinculadas à saúde nos orçamentos municipais e estaduais. Rio de Janeiro: Editora Museu da República; 2007.

11. Vianna SM. A seguridade social, o Sistema Único de Saúde e a partilha dos recursos. Saúde Soc 1992; 1:43-58.

12. Vianna SM. A seguridade social e o SUS: re-visitando o tema. Saúde Soc 2005; 14:7-22.

13. Subchefia para Assuntos Jurídicos, Casa Civil, Presidência da República. Emenda Constitucional $\mathrm{n}^{\circ}$. 29, de 13 de setembro de 2000. Diário Oficial da União 2000; 14 set.

14. Conselho Nacional de Saúde (CNS). Resolução $\mathrm{n}^{\circ}$. 322, de 8 de maio de 2003. Diário Oficial da União 2003; 8 mai.

15. Médici A. Gastos com saúde nas três esferas de governo: 1980-1990: o financiamento da saúde no Brasil. Brasília: Organização Pan-Americana da Saúde; 1994. (Série Economia e Financiamento, 4).

16. Costa RCR. Descentralização, financiamento e regulação: a reforma do sistema público de saúde no Brasil durante a década de 1990. Revista de Sociologia e Política 2002; 18:49-71. 
17. Faveret ACSC. A vinculação constitucional de recursos para a saúde: avanços, entraves e perspectivas. Ciênc Saúde Coletiva 2003; 8:371-8.

18. Ugá MAD, Piola SF, Porto SM, Vianna, SM. Descentralização e alocação de recursos no âmbito do Sistema Único de Saúde (SUS). Ciênc Saúde Coletiva 2003; 8:417-37.

19. Campelli MGR, Calvo MCM. O cumprimento da Emenda Constitucional $n^{\circ} .29$ no Brasil. Cad Saúde Pública 2007; 23:1613-23.

20. Dain S. Os vários mundos do financiamento da saúde no Brasil: uma tentativa de integração. Ciênc Saúde Coletiva 2007; 12 Suppl:1851-64.

21. Viana ALd'A, Novaes HMD, Silva JA, Rocha JSY, Ibañez N, Elias PEM. Financiamento e gasto com saúde nos municípios paulistas com população superior a 100 mil habitantes (2000-2003). São Paulo: Centro de Estudos de Cultura Contemporânea/Consórcio Medicina USP; 2006 (Cadernos de Atenção Básica: Estudos Descritivos, 2).

22. Fortes FBCP, Machado ENM, Matias BD. Gasto público com saúde nos municípios de Minas Gerais: 2000-2002. Divulg Saúde Debate 2007; 37:69-89.

23. Mendes A, Kayano J, Heimann LS, Junqueira V, Castro IEN, Ferreira MRJ, et al. Apuração do gasto SUS regionalizado no Estado de São Paulo. São Paulo: Instituto de Saúde; 2008 (Temas em Saúde Coletiva, 6).

24. Secretaria de Estado de Saúde de Mato Grosso. Plano diretor de regionalização da assistência à saúde 2005-2006. Cuiabá: Secretaria de Estado de Saúde de Mato Grosso; 2007.
25. Scatena JHG. Avaliação da descentralização da assistência à saúde no Estado de Mato Grosso [Tese de Doutorado]. São Paulo: Faculdade de Saúde Pública, Universidade de São Paulo; 2001.

26. Pereira J. Glossário de economia da saúde. In: Piola SF, Vianna SM, organizadores. Economia da saúde: conceito e contribuição para a gestão da saúde. $3^{\text {a }}$ Ed. Brasília: Instituto de Pesquisa Econômica Aplicada; 2002. p. 271-92.

27. Santos CH, Ribeiro MB, Gobetti SW. A evolução da carga tributária bruta brasileira no período 1995-2007: tamanho, composição e especificações econométricas agregadas. Brasília: Instituto de Pesquisa Econômica Aplicada; 2008. (Texto para Discussão, 1350).

28. Mendes A. Financiamento, gasto e gestão do SUS: a gestão descentralizada semiplena e plena do sistema municipal no Estado de São Paulo, 19952001 [Tese de Doutorado]. Campinas: Instituto de Economia, Universidade Estadual de Campinas; 2005.

29. Pochmann M. Tributação que aprofunda a desigualdade. Carta Social e do Trabalho 2008; 8:5-9.

30. Salvador E. Reforma tributária desmonta o financiamento das políticas sociais. Carta Social e do Trabalho 2008; 8:20-6.

Recebido em 05/Nov/2008

Versão final reapresentada em 02/Jun/2009

Aprovado em 29/Jul/2009 